EESTI NSV TEADUSTE AKADEEMIA TOIMETISED. VII KÖIDE

BIOLOOGILINE SEERIA. 1958, NR. 4

ИЗВЕСТИЯ АКАДЕМИИ НАУК ЭСТОНСКОЙ ССР. ТОМ VII СЕРИЯ БНОЛОГИЧЕСКАЯ. 1958, Nㅜ 4

\title{
SÜSTEMAATILIS-ÖKOLOOGILISI ANDMEID MÕNINGATE HUVITAVATE EESTI VESIKIRBULISTE (CLADOCERA) KOHTA
}

\section{A. MÄEMETS}

Käesolev kirjutis on mõeldud täienduseks autori varasemale Eesti vesikirbuliste faunat ja liikide ökoloogiat käsitlevale artiklile (Mäemets, 1958). Kirjutises on toodud Eesti rabadest leitud uue vesikirbuliste liigi Alona estonica n. sp. kirjeldus ja käsitletud täiendavalt mõningate meil haruldasemate liikide morfoloogiat, ökoloogiat ja levikut.

\section{Alona estonica n. sp.}

Mitmete Eesti rabade laugastes ja rabajärvedes leidus vähesel hulgal 우 vesikirbulisi perekonnast Alona, mis sarnanesid liigiga Alona costata G. O. Sars, kuid erinesid viimasest rea tunnuste poolest, eriti postabdoomeni ehituselt (joon. 1; mikrofotod 1 ja 2). Samuti erinesid nad liikidest Alona guttata G. O. Sars, A. karelica Stenroos, A. rectangula G. O. Sars ja teistest autorile tuntud Alona liikidest. Sellise liigi kirjeldust ei õnnestunud leida ka Leningradis NSVL TA Zooloogia Instituudis asuvast Behningi kataloogist, mis sisaldab materjali kogu maailma vesikirbuliste fauna kohta.

Alona estonica n. sp.

Alona costata G. O. Sars

1. Pikkus $0,3-0,5 \mathrm{~mm}$.

2. Postabdoomen suhteliselt jässakas.

3. Postabdoomeni ülaserva distaalne nurk ümardunud ja distaalselt väljaulatuv.

4. Pärakuava serv märgatavalt nõgus.

5. Pärakuava serv kogu ulatuses kaetud vördlemisi hästi nähtavate harjaste reaga.

6. Pärakuava proksimaalne nurk väga tugevalt väljaulatuv.

7. Esineb köbrukestega vorm f. tuberculata.

8. Esineb väga happelise aktiivse reaktsiooniga vees $(\mathrm{pH}<6)$.

9. + o leiti mai algusest novembri keskpaigani. Efippiumiga 우 우 leitud veel isegi mitte novembris.
1. Pikkus tavaliselt $>0,5 \mathrm{~mm}$.

2. Postabdoomen suhtelișelt pikk ja sale.

3. Postabdoomeni ülaserva distaalne nurk terav ja ei ulatu distaalselt välja.

4. Pärakuava serv peaaegu sirge.

5. Pärakuava serval vaid distaalses osas vähesed väikesed harjased.

6. Pärakuava proksimaalne nurk vähem väljaulatuv.

7. Köbrukestega vormi ei ole täheldatud.

8. Esineb peamiselt neutraalse ja leelisese aktiivse reaktsiooniga vees. ${ }^{1}$

9. $\&$ o esinevad tavaliselt maist septembrini-oktoobrini. Juba septembris-oktoobris esinevad efippiumiga + ㅇ.

1 Eestis leitud pH väärtuste 7,0-9,2 juures (Mäemets, 1958). Ka Poulseni (1928) järgi levib $A$. costata põhiliselt nôrgalt happelise või leelisese aktiivse reaktsiooni juures. 
Võrreldes antud liiki (우) teiste Alona liikidega näib, et uus kirjeldatav liik on oma morfoloogialt küllalt lähedane liigile $A$. costata. Nii on suur sarnasus silmatäpi paigutuses ja suuruses, ees- ja tagatundlate ning huule ehituses ${ }^{2}$ ja mitmetes teistes tunnustes. Kuid esineb ka rida olulisi morfoloogilisi ja ökoloogilisi erinevusi, mis lasevad liiki hästi eristada liigist $A$. costata. Olevaate nimetatud erinevustest annab tabel (vt. ka jooniseid 1,5 ja 2 ning mikrofotot 2 ).

Tänu postabdoomeni vähesele muutlikkusele ${ }^{3}$ ja mitteallumisele tsüklomorfoosile on tema ehitus eriti tähtsaks tunnuseks morfoloogiliselt võrdlemisi sarnaste perekond Alona liikide eristamisel. Silmas pidades fakti, et kirjeldatava liigi postabdoomeni ehituses puudub varieerumine, samuti ïleminekud liigile $A$. costata või teistele liikidele, ühtlasi arvestades teisi erinevusi, arvab autor, et on tegemist uue, seni veel kirjeldamata, rabaveekogudele spetsiifilise Alona liigiga.

Liigi kirjeldus. ㅇ. Pea ja koja ülaserv on korrapäraselt kumerdunud. Koja taga-ülaserv ja taga-alanurk ümardunud, tagaserv nõrgalt kumer, alaserv peaaegu sirge või veidi nõgus. Koja alaserv kaetud suhteliselt pikkade karvadega. Nokis (rostrum) lai ja nüri ning suunatud alla. Pea alaserv S-laadiliselt kõverdunud. Koja retikulatsioon nõrkade pikitriipudena, mis vahel vaevalt märgatavad, või koda kaetud mügarate ridadega (f. tuberculata n. forma - joon. 1,4). Silm veidi suurem või sama suur kui silmatäpp. Viimane paikneb lähemal silmale kui nokise tipule.

Eestundlad lühikesed ja ei ulatu nokise tipuni. Eestundlate eesserval rida ogakesega varustatud sälke; tagaserva distaalse otsa lähedal meeleharjas ja näsa (papill) (joon. 1, 1).

Tagatundlatel suhteliselt suured ogad välisharu esimesel ja mõlema haru distaalsel lülil. Huul distaalselt ahenev, nõrgalt lainelise servaga (joon. 1, 3). Huule alaserval 2 karvakimpu.

Postabdoomen suhteliselt lühike, distaalselt ahenev (joon. 1, 5). P ostabdoomeni ülaserva dista lne nurk ümardunud ja distaalselt väljaulatuv, mistõtu selle nurga ja küüniste vahele jääb võrdlemisi sügav väljalõige. Postabdoomeni ülaserval pärakuhammaste (anaalhammaste) rea proksimaalses os as nurk, kuna pärakuava kohal on ülaserv nõgus. Pärakuava proksima lne nurk terav ja tugevalt väljaulatuv. Distaalselt veidi suurenevate pärakuhammaste arv kummaski reas $9-12$, enamasti 10-11. Pärakuhammaste rida jätkub proksimaalselt (pärakuava kohal) väikeste harjaste reana, mis ulatub kuni pärakuava proksimaalse nurgani (harjased tavaliselt rühmiti, $2-3$ r ühm a). Postabdoomeni alaserva proksimaalsel osal harilikult väljaulatuv nurk. Küünised pikad, vähe painutatud, kumbki neist ühe alusogaga.

Loomad värvusetud või kollased. Pikkus $0,33-0,50 \mathrm{~mm}$; partenogeneetiliste munadega 우 ㅇ pikkus $0,39-0,50 \mathrm{~mm}$.

ô $\hat{o}$ ei ole leitud kuni 1958. a. suveni, kuid siis sai käesoleva artikli autor neid Meelva järvest (3 eks.). Alona estonica isased erinevad Alona

I Kirjeldatavale liigile sarnase ehitusega eestundlad ja huul on ka liigil A. costata. Lilljeborgi klassikalises töös (Lilljeborg, 1900) toodud A. costata eestundla ja huule joonis (tahvel LXVIII, 11) ei ole selles suhtes päris täpne.

3 Real Alona likidel (A. affinis (Leydig), A. quadrangularis G. O. Sars, A. rectangula G. O. Sars, A. costata G. O. Sars jt.) on siiski täheldatud teatavate anomaaliate esinemist postabdoomeni ehituses (Ramult, 1930). Samuti varieerub pärakuhammaste arv, 
costata isastest oma postabdoomeni ehituse poolest väga selgelt: küünised on lühemad, esineb küünise alusoga, peniselaadne jätke on pikem, ülaserva distaalne nurk suur ning ümmargune jne. (Isaste kirjelduse ja joonised esitab autor tulevikus eraldi artiklis.)

Diferentsia aldiagnoos: Omab iseloomuliku postabdoomeni üldkuju ja varustuse.

$\mathrm{T}$ ü ü p: Nr. 1 † (preparaat glütseriin-želatiinis) ENSV TA Zooloogia ja Botaanika Instituudis.

T ü ü bi l e i u k oht: Laukast (nn. Saarelaugas) Loosalu rabas (Rapla raj.) 16. XI 1955. a.

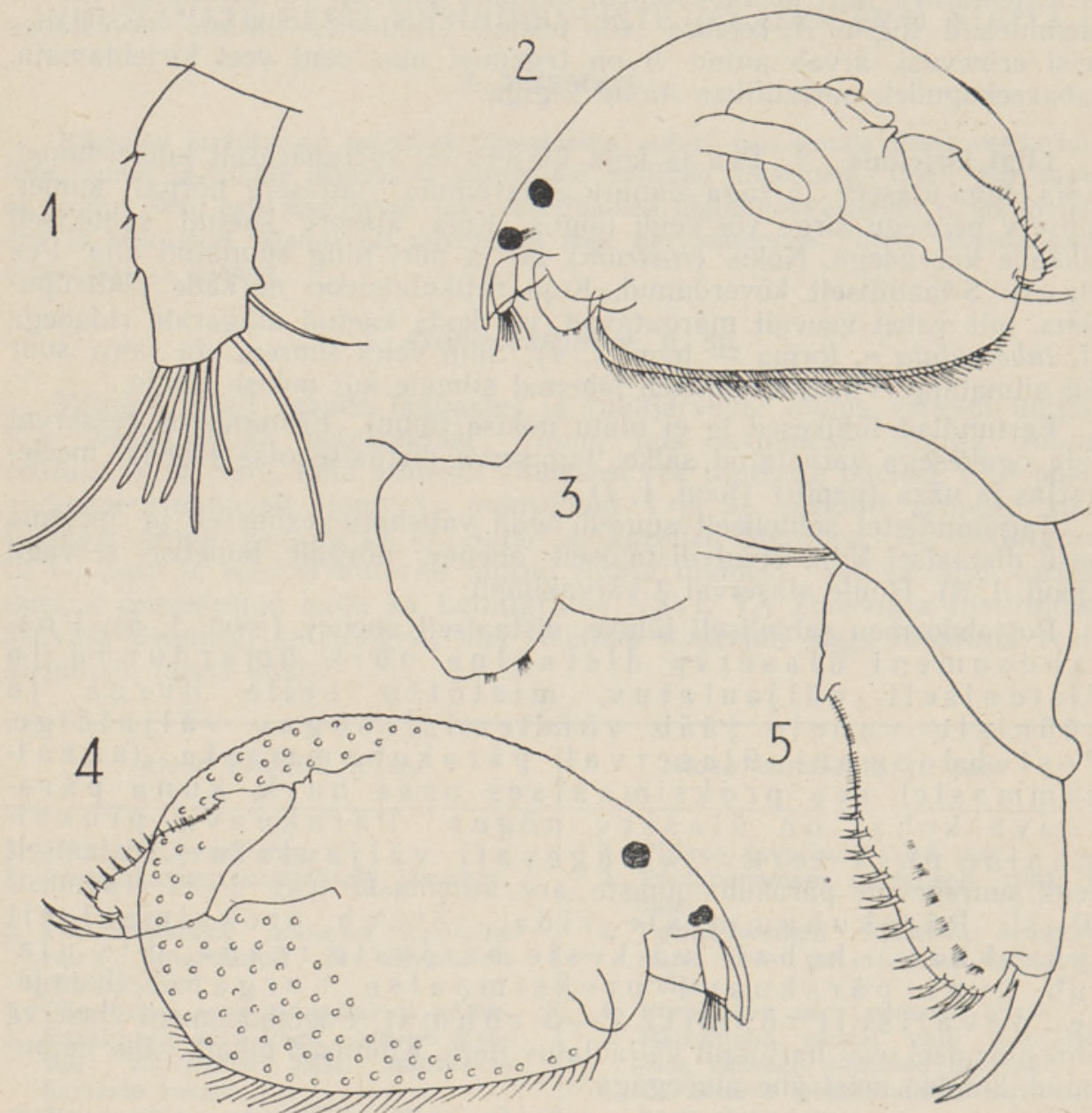

Joon. 1. Alona estonica n. sp. $+: 1$ - eestundel, $2-$ üldvaade (tüüpiline vorm), 3 - huul, 4 - üldvaade (f. tuberculata), 5 - postabdoomen.

Eestis on kõnealust liiki leitud seni 9 veekogust (vt. levikukaart, joon. 3), kokku 17 eksemplari, neist 4 isendit f. tuberculata.

Teised leiukoh'a d: Kirikumäe järv - f. tuberculata - 1 kest (21. VI 1952); laugas Varudi rabas -2 eks., neist 1 kest (VI 1953, leg. M. Pork); rohtunud lombid Männiku rabas -2 eks. (2. V 1955); Tooma Sinilaugas -1 kest (10. XI 1955); laugas Loosalu rabas (Saarelaugas) -3 eks. (2. VII 1956); Loosalu järv - f. tuber- 
culata -2 eks. (16. XI 1955, 2. VII 1956); laugas Tänavjärve rabas -2 eks. (6. VIII 1956); laugas Võlla rabas -2 eks. (30. VII 1957); laugas Nätsi nabas - f. tuberculata -1 eks. (1. VIII 1957).

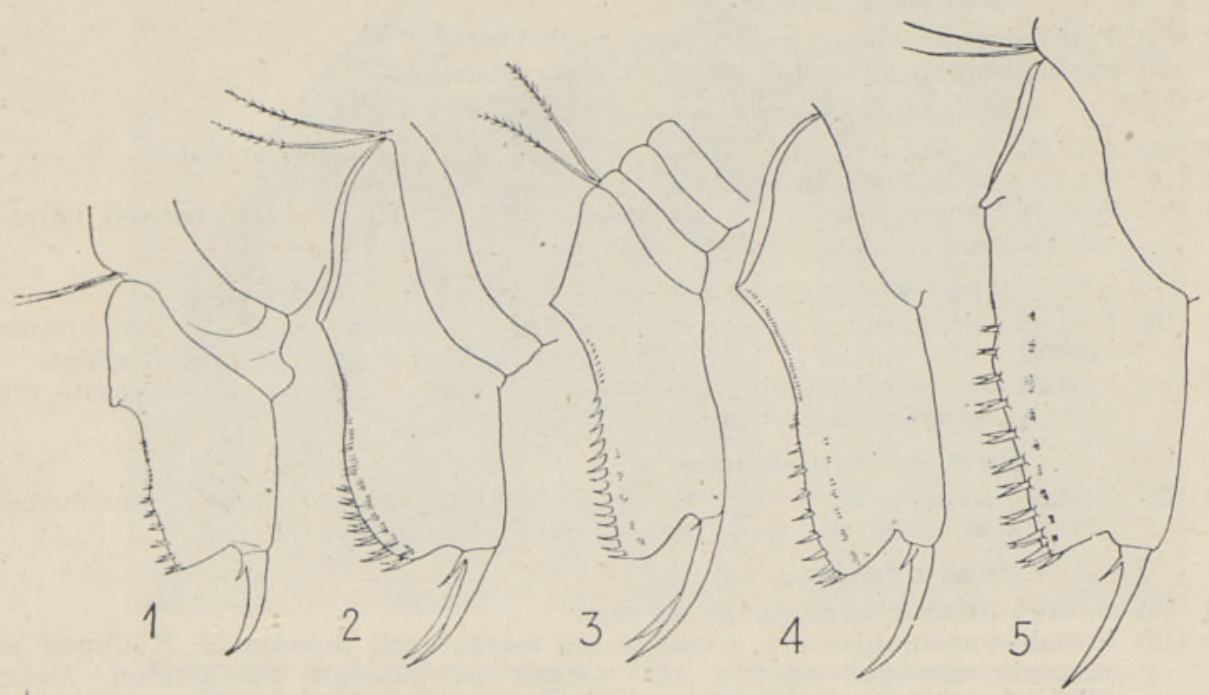

Joon. 2. Alona estonica'le lähedaste Alona liikide postabdoomenid: 1 - Alona guttata G. O. Sars; 2 - Alona rectangula G. O. Sars; $3,4-$ Alona kanelica Stenroos (3 - Herri (1917) järgi; 4 - Stenroosi (1897) järgi); 5 - Alona costata G. O. Sars.

A. estonica esines rabalaugastes ja -järvedes peamiselt kaldavöös, kusjuures täiskasvanud $\circ$ ㅇ esinesid 2 . V -16 . XI. Liiki leiti vee temperatuuril alla $15,8^{\circ}, \mathrm{pH}$ väärtuste 4-6 ja $\mathrm{Ca}^{*}{ }^{-}$-sisalduse $2,4-$ $4,6 \mathrm{mg} / 1$ juures. Liiki leiti tavaliselt koos selliste Eesti rabades levivate liikidega nagu Holopedium gibberum Zaddach, Scapholeberis microcephala (Lilljeborg MS) G. O. Sars, Bosmina c. obtusirostris G. O. Sars, Acantholeberis curvirostris (O. F. Müller), Chydorus ovalis Kurz, Acanthodiaptomus denticornis (Wierz.), Heterocope saliens (Lilljeborg) jt.

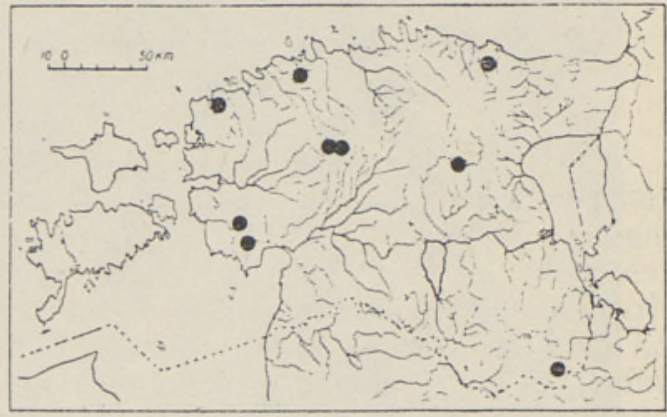

Joon. 3. Alona estonica sp. nov. leiukohad Eesti NSV-s.

Kõigi Eestis esineda võivate Alona liikide määramiseks ja Alona estonica eristamiseks + ㅇ järgi tuuakse alljärgnev määramistabel.

1 (2) Postabdoomeni pärakuhammaste rea mõned kõige distaalsemad hambad märgatavalt pikemad (umbes $2-3$ korda) ülejäänutest.

\section{Alona tenuicaudis $\mathbf{G}$. O. Sars ${ }^{4}$}

2 (1) Postabdoomeni pärakuhammaste rea distaalsed hambad ei ole märgatavalt pikemad ülejäänutest.

3 (6) Postabdoomeni ülaserva distaalne nurk ei ole ümardunud.

4 (5) Postabdoomen suhteliselt lühike, 6-10 vôrdlemisi väikese pärakuhambaga kummaski reas.

4 Rida autoreid, nagu Birge (1918), Behning (1941) jt. eraldavad liigi iseseisvasse perekonda Oxyurella Dybowski et Grochowski. 


\section{Alona guttata G. O. Sars}

5 (4) Postabdoomen suhteliselt pikk, 7-14 (tavaliselt 10-13) võrdlemisi suure distaalselt suureneva pärakuhambaga kummaski reas.

\section{Alona costata G. O. Sars}

6 (3) Postabdoomeni ülaserva distaalne nurk ümardunud.

7 (8) Postabdoomen distaalses osas tugevasti laienenud.

\section{Alona intermedia $\mathbf{G}$. O. Sars}

8 (7) Postabdoomeni distaalne osa ei ole või on väga vähe laienenud.

9 (14) Väikesed liigid, pikkusega alla $0,5 \mathrm{~mm}$.

10 (11) Postabdoomeni ülaserva ümardunud distaalne nuık ei ole distaalselt väljaulatuv ning ei ulatu seetõttu küüniste-alla.

\section{Alona rectangula $\mathbf{G}$. O. Sars}

11 (10) Postabdoomeni ülaserva ümardunud distaalne nurk distaalselt väljaulatuv, mistõttu selle nurga ja küüniste vahele jääb võrdlemisi sügav väljalõige.

12 (13) Postabdoomen suhteliselt sale. Postabdoomeni ülaserv pärakuhammaste rea ulatuses enam-vähem sirge.

\section{Alona karelica Stenroos}

13 (12) Postabdoomen võrdlemisi jässakas. Postabdoomeni ülaserv moodustab pärakuhammaste rea proksimaalses osas väljaulatuva nurga,

Alona estonica n. sp.

14 (9) Suured liigid, pikkusega üle $0,5 \mathrm{~mm}$.

15 (16) Postabdoomeni ülaserva distaalne osa märgatavalt puhetunud. Küünised ja viimaste alusogad siledad või vaevalt märgatavalt karvastatud. Nokis lühike ja nüri. 5 paari jalgu.

\section{Alona quadrangularis (O. F. Müller)}

16 (15) Postabdoomeni ülaserva distaalne osa väga vähe puhetunud, mistõttu ülaserv peaaegu sirge. Küünised ja viimaste alusogad selgelt karvastatud. Nokis pikk ja terav. 6 paari jalgu.

\section{Alona affinis (Leydig)}

\section{Scapholeberis microcephala (Lilljeborg MS) G. O. Sars}

(Syn. Scapholeberis reticulata Linko, 1900)

Seda seni väga haruldast vesikirbulist (joon. 4, 1; mikrofoto 4) on leitud peamiselt rabadest, kus ta teatavais biotoopides on tavaline, kuid enamasti väikesearvuline. Liik elab Sphagnum'iga täitunud hälvetes ja laugastes, esinedes siin harilikult koos teiste vesikirbuliste liikidega, nagu Acantholeberis curvirostris (O. F. Müller), Chydorus ovalis Kurz jt. Eestis on rida leide ka järvede kaldavööst tarnade, ubalehtede ja vesirooside vahelt. S. microcephala esines meil oligo- ja mesotroofsetes peamiselt polühumoossetes veekogudes (põhiliselt eutroofses Veisjärves leiti vaid 1 eks. rabakalda alt!) $\mathrm{pH}$ väärtuste $4-7,6$ juures (eksperimentaalsetes tingimustes talub hästi vee aktiivset reaktsiooni kuni 9,0 (Яценко, 1928) ). Liiki konstateeriti vee temperatuuril $4-22^{\circ}$, kusjuures $4^{\circ}$ juures esines vaid üksikuid $ㅇ$ efippiumiga isendeid (Tähtvere rabas 16. XI 1957). 우 ㅇ leiti Eesti veekogudes maist kuni oktoobrini, kuna $\hat{o} \hat{o}$ ei ole õnnestunud leida. Upsala lähedal Rootsis ilmusid of $\hat{s}$ oktoobris (Lilljeborg, 1900).

Boreaalne liik, kelle pealevikuala näib olevat taigavööndis või veelgi põhja pool. Senised leiud pärinevad palearktilisest alamvaldkonnast Skandinaaviast Baikalini, kusjuures üksikud kõige lõunapoolsemad leiukohad on Poolas ja Tšernigovi ümbruses. Autorile teadaolevail andmeil on seni maailmas umbes 35 kõnesoleva liigi leiukohta, neist 10 Eesti NSV territooriumil. Liigi vähest leidmist on põhjustanud nähtavasti kaks asjaolu: 1) rabaveekogude vähene uurimine ja 2) liigi segiajamine küllalt sarnase liigiga Scapholeberis mucronata (O. F. Müller). 


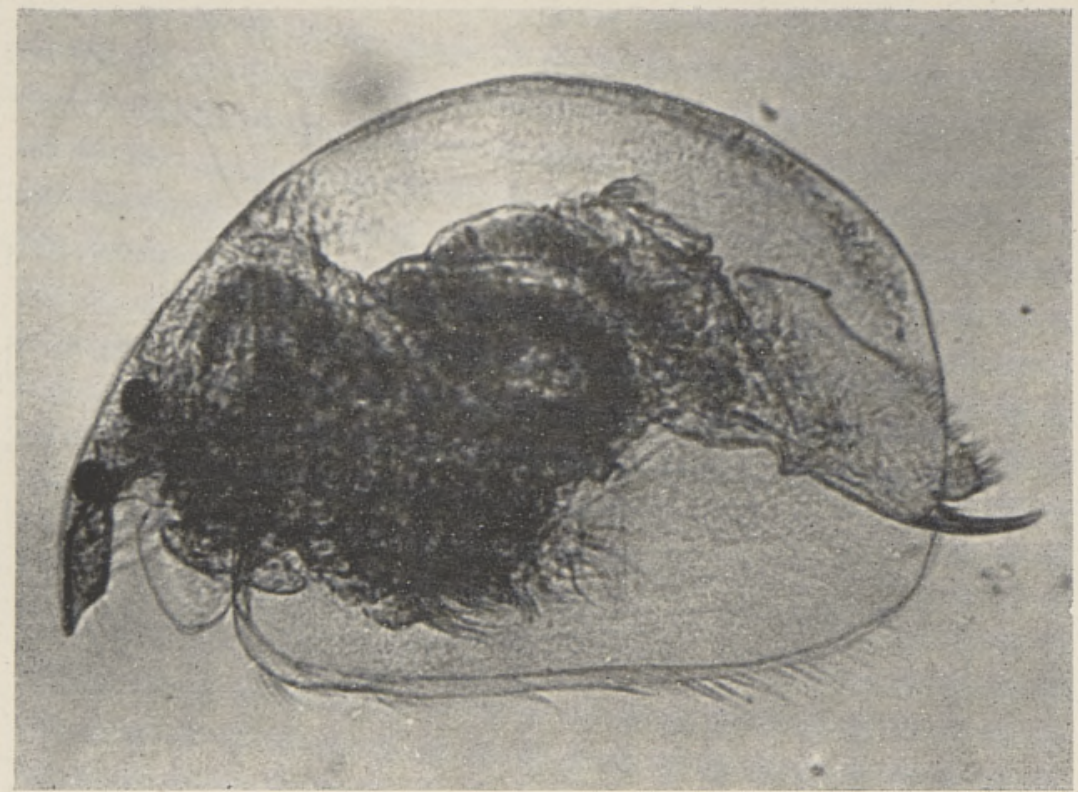

Mikrofoto 1. Alona estonica sp. nov. 우 üldvaade (suurendus umbes $200 \times$ ). Leitud laukast (Saarelaugas) Loosalu rabas 16. XI 1955.

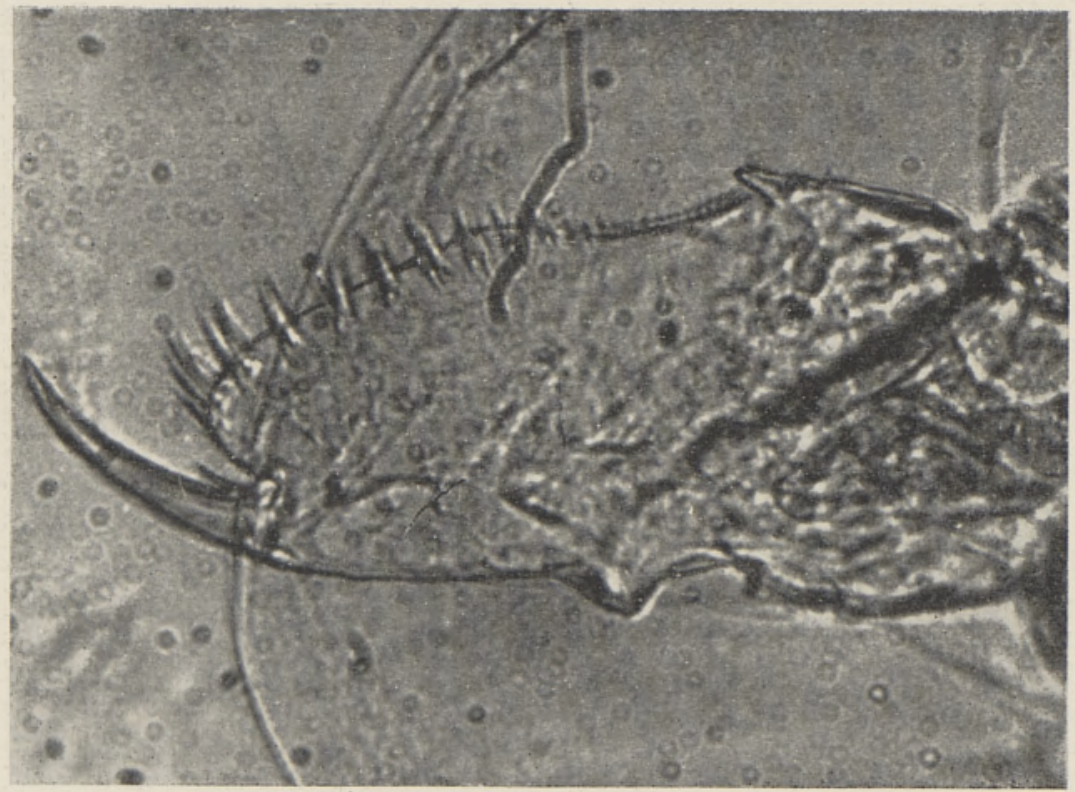

Mikrofoto 2. Alona estonica sp. nov. o postabdoomen (suurendus umbes $410 \times$ ). Leitud laukast Tänavjärve rabas 6 . VIII 1956 . 


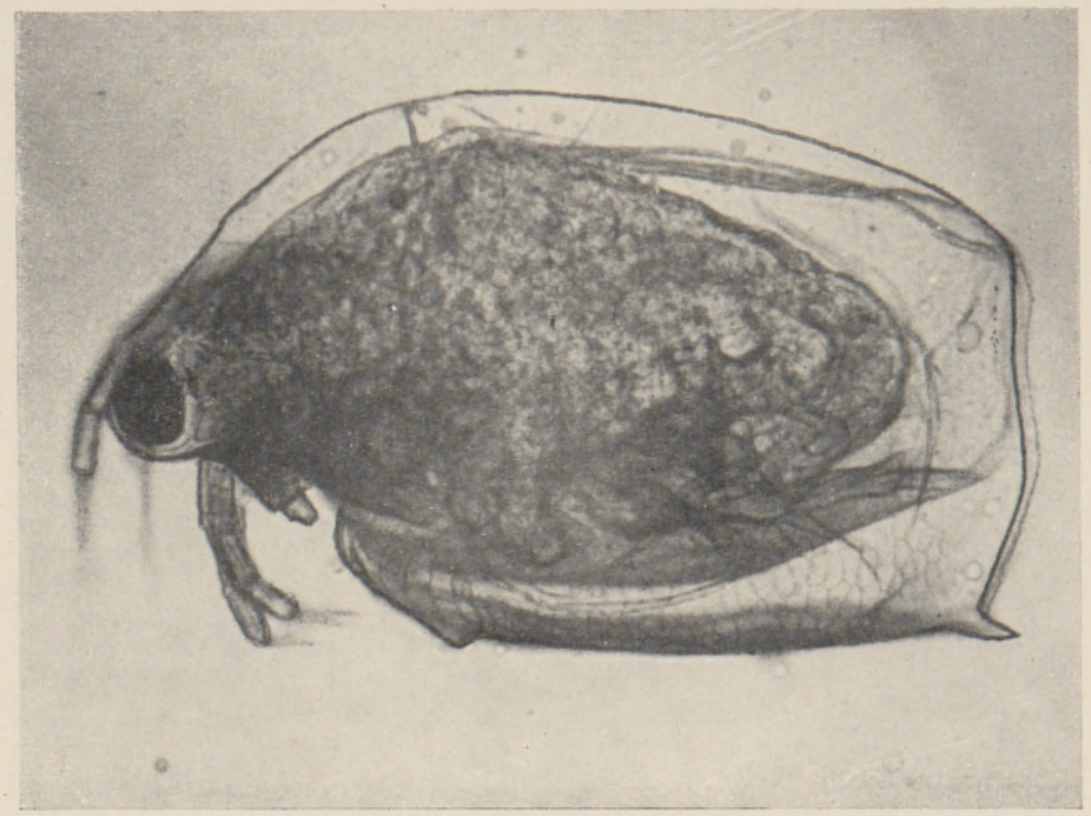

Mikrofoto 3. Scapholeberis microcephala (Lilljeborg MS) G. O. Sars. üldvaade (suurendus umbes $165 \times$ ). Leitud laukast Tänavjärve rabas 6. VIII 1956.

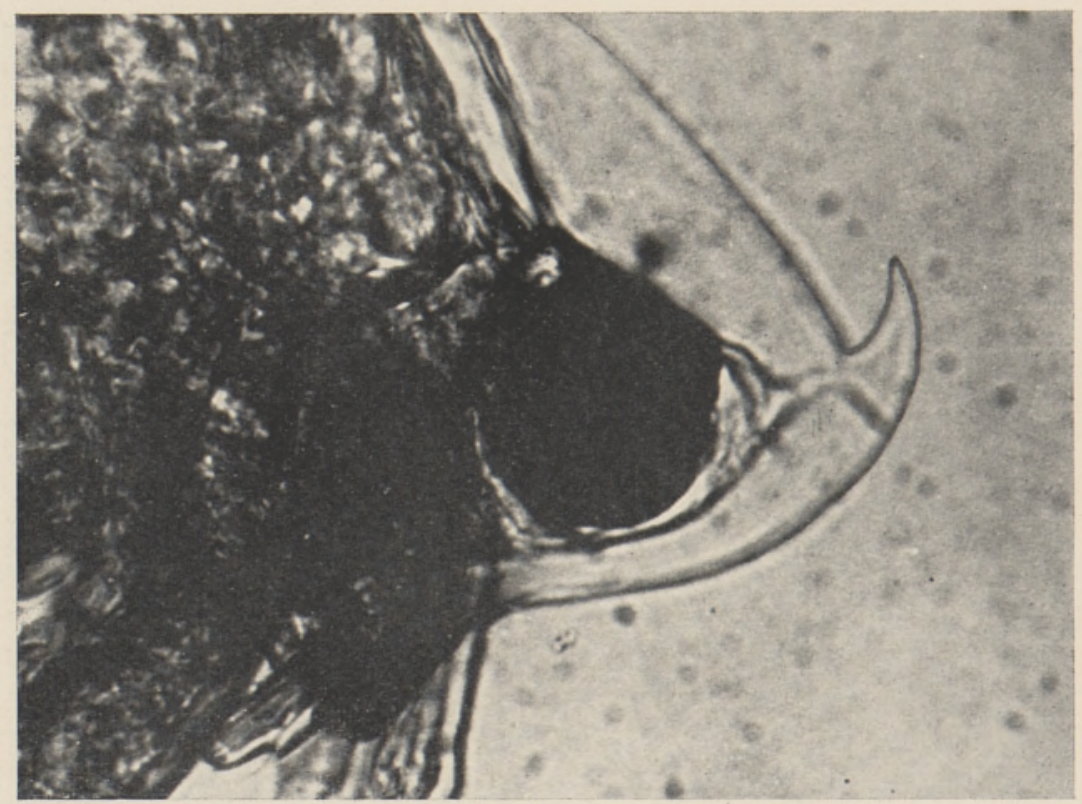

Mikrofoto 4. Scapholeberis microcephala f. subcornuta G. O. Sars. ㅇ pea (suurendus umbes $330 \times$ ). Leitud Lindjärvest 19. IX 1956. 
Eriti vähe on leitud vormi S. microcephala f. subcornuta G. O. Sars (Sars, 1890). Seda ei ole leidnud Lilljeborg (1900); samuti ei maini teda Novikov (1910), Vereštšagin (1912), Korde (1926), Oparina-Haritonova (1925), Sidorov ja Vinberg (1928), Ocioszynska-Bankierowa (1934), Behning (1941) jt. autorid, kes käsitlevad liiki S. microcephala. Põhivormi ja f. subcornuta vahel leidis käesoleva kirjutise autor kõiki üleminekuid. Nii esines Loosalu rabas asuvas laukas ühes ja samas proovis isendeid välja-

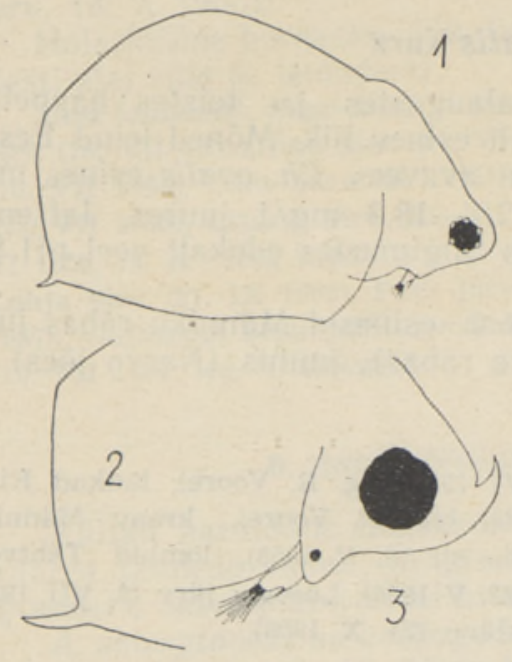

Joon. 4. Scapholeberis microcephala (Lilljeborg MS) G. O. Sars: 1 - üldvaade (tüüpiline vorm Stenroosi (1897) järgi), 2 f. subcornuta G. O. Sars sabaoga (mucro), 3 - f. subcornuta G. O. Sars pea.
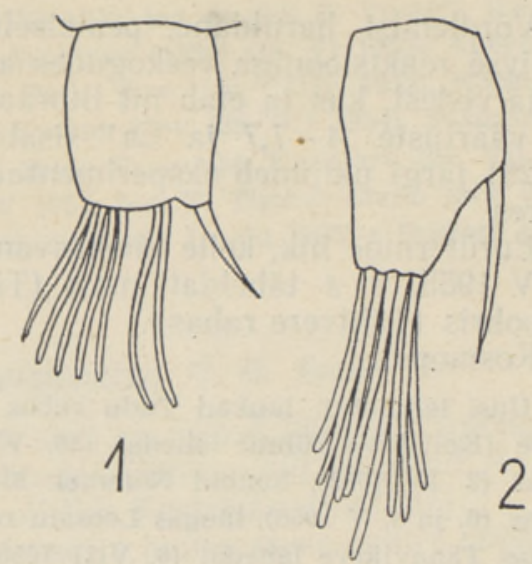

Joon. 5. Scapholebreris mucronata (O. F. Müller) ja Scapholeberis microcephala (Lilljeborg MS) G. O. Sars eestundlad: $1-S$. mucronata (Lilljeborgi (1900) järgi), $2-S$. microcephala (Stenrocsi (1897) järgi).

kujunenud sarvega, sarve algega ja hoopis ilma sarveta (23. VII 1955). Eestis leiti $S$. microcephala f. subcornuta't 6-s veekogus. Näib, et nimetatud vormi, mis esineb peamiselt järvedes, võib eriti kergesti ära segada vormiga $S$. mucronata f. cornuta Schoedler. Seetõttu tuuakse artiklis S. microcephala f. subcornuta pea ja sabaoga (mucro) joonised (joon. 4, 2, 3; mikrofoto 5) ning vaadeldakse lühidalt tema morfoloogiat.

S. microcephala f. subcornuta peas asetsev sarv on suunatud veidi ülespoole jå on väiksem kui vormil $S$. mucronata f. cornuta. Sabaoga on tal väiksem kui S. mucronata f. cornuta'l, kuid sageli suurem kui vormil S. microcephala typica. S. microcephala f. subcornuta retikulatsioon ei ole sageli nii selgelt välja kujunenud kui tüüpilisel vormil, mistõttu ta sarnaneb vormiga $S$. mucronata f. cornuta. Kõige eelöeldu põhjal tuleb liikide $S$. mucronata ja $S$. microcephala teineteisest eraldamisel võtta põhikriteeriumiks eestundlate ehitus, mis on kummalgi väga iseloomulik (joon. 5) ja mikroskoobi suurel suurendusel $(7 \times 40)$ kergesti vaadeldav. S. microcephala typica 우 pikkus oli $0,43-0,74 \mathrm{~mm}$ (23 mõõdetud isendit 6 -st veekogust), S. microcephala f. subcornuta o 우 pikkus $0,32-0,70 \mathrm{~mm}$ (27 mõõdetud isendit 6 -st veekogust).

Lisaks varasematele leiukohtadele (Mäemets, 1958) leiti liiki järgmistes veekogudes: f. subcornuta - Sepa järv (404 ?) $)^{5}$ (19. VIII 1943, leg. R. Voore), Rõuge

\footnotetext{
${ }^{5}$ Järve number Riikoja (1934) järgi.
} 
Kõrbjärv (4. VII 1955, leg. I. Veldre), laugas Loosalu rabas (23. VII 1955, leg. I. Veldre), Mustjärv (918) (17. VI 1956, leg. M. Sõrmus), Veisjärv (26. VI 1956, leg. M. Sõrmus), Lindjärv (19. IX 1956); typica - Meelva järv (23. V 1957, leg. T. Timm).

Väljaspool Eesti NSV territooriumi määras autor liiki (typica) veel Leedu NSV-s Kamanose raba laukast (11. VII 1957, leg. V. Kõvask). Kõigis neis veekogudes esines liiki vähesel hulgal (välja arvatud Mustjärv, kus teda esines arvukalt).

\section{Chydorus ovalis Kurz}

Võrdlemisi haruldane, peamiselt rabalaugastes ja teistes happelise aktiivse reaktsiooniga veekogudes arvukalt esinev liik. Mõned leiud Eestis ka järvedest, kus ta elab nii litoraalis kui avavees. Ch. ovalis esines meil $\mathrm{pH}$ väärtuste $4-7,7$ ja $\mathrm{Ca}{ }^{*}$-sisalduse $2,4-18,8 \mathrm{mg} / 1$ juures. Jatsenko (1928) järgi paljuneb eksperimentaalsetes tingimustes edukalt veel $\mathrm{pH} 9,0$ juures.

Eurütermne liik, kelle täiskasvanud $q$ 우 esinesid Männiku rabas juba 2. IV 1955. ô $\hat{o}$ täheldati mais (Tähtvere rabas), juunis (Narva jões) ja oktoobris (Tähtvere rabas).

Kosmopoliit.

Uusi leiukohti: laukad Tudu rabas (28. VI 1939, leg. R. Voore), laukad Kivijärve (Koitjärve rühm) lähedal (28. VIII 1943, leg. R. Voore), kraav Männiku rabas (2. IV 1955), lombid Nõmmel Mustamäe all (8. V 1955), lombid Tähtvere rabas (6. ja 8. V 1956), laugas Loosalu rabas (23. V 1956), Loosalu järv (2. VII 1956), laugas Tänavjärve lähedal (6. VIII 1956), Veisjärv (24. X 1956).

\section{Chydorus latus G. O. Sars}

Autori varasemas töös (Mäemets, 1958) väga haruldaseks peetud liik. Nagu näitavad hilisemad analüüsid ja määramata jäänud preparaatide läbivaatamine, esineb nimetatud liik sagedamini kui esialgu võis oletada, kuid ei ole siiski mitte tavaline.

Liigi määramist raskendab tema suur sarnasus liigiga Chydorus sphaericus O. F. Müller, kellest ta erineb suuruselt, üldkujult ja postabdoomeni varustuselt, kusjuures nimetatud erinevused ei ole kuigi suured.

Liiki on seni leitud peamiselt järvede litoraalist, kus ta on tavaliselt väikesearvuline. Esineb ka väikeveekogudes. Leiud põhiliselt oligo- kuni mesohumoossetest veekogudest, kuna veekogu troofsuse suhtes on Ch. latus eurüplastiline. Siiski väärib mainimist tema rohke esinemine oligotroofse Martiska järve (Kurtna rühm) litoraalis Carex sp. vahel (14. V 1958). Võib Stenroosi (1895) ja Lilljeborgi (1900) andmeil esineda ka f̂iimvees. Leiti $\mathrm{pH}$ väärtuste $7,0-9,0$ juures. Eurütermne. Täiskasvanud $q$ $\circ$ esinesid maist alates. Rootsis Upsala lähedal leiti of o maist oktoobrininovembrini, $\hat{t}$ of septembris-oktoobris (Lilljeborg, 1900).

Holarktiline liik.

Uusi leiukohti: Prossa järv (28. VI 1951), Pikkjärv (569) (11. ja 27. VII 1951, 25. VI 1957), Soitsjärv (18. VII 1951), Karijärv (9. VIII 1951), Pangodi järv (10. VIII 1951), Neitsijärv (13. VIII 1951), Kise järv (19. VI 1952), Kahrila järv (6. VII 1952), Pikkjärv (1319) (18. VII 1952), Rõuge Suurjärv (2. VII 1955), lombid Kauksi soos (21. V 1957, leg. T. Timm), Martiska järv (14. VIII 1957, 14. V 1958).

\section{Chydorus piger G. O. Sars}

Võrdlemisi vähe leitud liik. Eestis leitud vaid järvedest, kuid alati vähesel hulgal. Sagedamini esineb liivase põhjaga litoraalis pilliroo, kõrkja ja 
konnaosja vahel; reas madalates järvedes levib ka pelagiaalis. Leitud pōhiliselt oligo- ja mesotroofsetest, harva eutroofsetest järvedest. Veekogu humoossuse suhtes võrdlemisi eurüplastiline, kuid eelistab ilmselt oligo- ja mesohumoosseid järvi. Leiti $\mathrm{pH}$ väärtuste $6,5-9,2, \quad \mathrm{Ca}{ }^{*}$-sisalduse $3,4-58,9 \mathrm{mg} / 1$ ja $\mathrm{HCO}_{3}$-sisalduse $6,1-213,6$ juures. Liigi esinemist limiteerivaks teguriks on nähtavasti veekogu troofsus või hapnikuolud.

Ch. piger esines vee temperatuuril $7,5-22,8^{\circ}$, kusjuures 우 우 leiti maist septembrini (vee temperatuuril $12-22,8^{\circ}$ ), of $\hat{o}$ ilmusid oktoobris (Saadjärv, 18. X 1956).

Holarktiline boreaalne liik, kes Eesti NSV-s on laiemalt levinud MadalEesti alal (üle $2 / 3$ leidudest).

Uusi leiukohti: Suur-Seapilii järv (27. VII 1943, leg. et det. R. Voore ${ }^{6}$ ), Kaiavere järv (16. VII 1951), Hino järv (17. VI 1952), Saarjärv (1550) (18. VI 1952), Aheru järv (16. VII 1952), Oisu järv (4. VIII 1952), Kalli järv (16. VIII 1952), Konsu järv (23. VII 1953), Uljaste järv (21. VII 1954), Kurtna järv (26. VII 1954), Saadjärv (22. VI 1955, 18. X 1956), Ermistu järv (18. VII 1956), Saaremaa Karujärv (24. VII 1956), Lohja järv (21. IX 1956), Pulli järv (26. V 1957, leg. T. Timm), Endla järv (27. VI 1957). Väljaspool Eesti NSV-d määras autor liiki veel Leedu NSV-s Dusiose järvest (19. VII 1957, leg. V. Kõvask).

\section{Anchistropus emerginatus G. O. Sars}

Küllalt haruldane liik, keda Eestis seni on leitud üksnes järvede litoraalist taimede vahelt. Kõigis leiukohtades esines vaid üksikuid $A$. emerginatus'e eksemplare; veidi arvukam oli liik Köstrejärves (1337).

A. emerginatus on veekogude troofsuse ja humoossuse suhtes võrdlemisi eurüplastiline. Leiti $\mathrm{pH}$ väärtuste $6,6-8,2, \mathrm{Ca}$ - -sisalduse $7,0-54,9 \mathrm{mg} / 1 \mathrm{ja}$ $\mathrm{HCO}_{3}{ }^{\prime}$-sisalduse 5,5-198,3 mg/1 juures. Kõik leiud Eestis (erand Parika järv) on tehtud juuli- ja augustikuudel. $\hat{o} \hat{o}$ ei ole Eestis leitud. Rootsis (Upplandis) on $\hat{\delta}$ o leitud väga väikesel hulgal septembris-oktoobris (Lilljeborg, 1900).

Liik levinud vaid palearktilises alamvaldkonnas. Leiud põhiliselt KõrgEesti alalt.

Uusi leiukohti: Pikkjärv (569) (27. VII 1951), Saadjärv (25. VII 1951), Karijärv (9. VIII 1951), Pikkjärv (1319) (18. VII 1952), Tündre järv (30. VII 1952), Parika järv (18. VI 1953), Konsu järv (23. VII 1953), Uiakatsi järv (8. VII 1954), Köstrejärv (10. VII 1956), Kivijärv (3, VII 1957).

Lisaks eespool toodud liikidele on autoril üksikuid haruldaste vesikirbuliste leide veel tervest reast veekogudest, kellede avaldamine peaks pakkuma laiemat faunistilist huvi.

Limnosida frontosa G. O. Sars: Lavassaare järv (20. VI 1953).

Ceriodaphnia megalops G. O. Sars: Ubajärv (10. VII 1952), Pikrijärv (12. VIl 1956), hõõtsik Võhanđu jõe ääres (22. V 1957), luhalomp Jägala jõe ääres (18. VI 1957), Tooma Kõrtsijärv (26. VI 1957), järvik Majori järve lähedal (14. VII 1957), linaligu Lõõdla järve juures (27. VII 1957).

Ceriodaphnia rotunda G. O. Sars: Pikkjärv (569) (27. VII 1951), lombid Emajõe luhal (8. VI 1956), linaligu Pupastvere Umbjärve ääres (4. VII 1956), allikaline lomp Haanjas (17. VII 1957).

Ilyocryptus sordidus (Lieven): Lavassaare järv (20. VI 1953), Loosalu järv (16. XI 1955), Tooma Männikjärv (26. VI 1957).

${ }^{6}$ Lisaks eelmises artiklis (Mäemets, 1958) kasutatud R. Voore kogutud zooplanktoni proovidele on autor saanud mõninga:d uusi R. Voore käsikirja'isi materjale Põhja-Eesti järvede kohta, millest proove säilinud ei ole. R. Voore andmed on tähistatud lühendiga «det, R. Voore». 
Ilyocryptus agilis Kurz: Soojärv Harju rajoonis (2. VII 1943, leg. et det. R. Voore), Soitsjärv (23. VI 1957).

Ilyocryptus acutifrons G. O. Sars: Lavassaare järv (20. VI 1953), Mustjärv (918)

(9. V 1957).

Ophryoxus gracilis G. O. Sars: Kise järv (18. VI 1953).

Kurzia latissima (Kurz): Pikkjärv (569) (2 우 우 11. VII 1951).

Alona intermedia G. O. Sars: Tänavjärv (25. VII 1955), Palujärv (1099) (22. X 1957).

Leydigia leydigi (Schoedler): Allikjärv (187) (21. VI 1943, leg. et det. R. Voore), Jõemõisa järv (29. VII 1951), Pikkjärv (1319) (18. VII 1952), Tündre järv (30. VII 1952), Kariste järv (3. VIII 1952), Pikkjärv (1230) (14. VI 1953), Ähijärv (21. VII 1957), Vissi järv ja kanal Vissi ja Viisjaagu järve vahel (17. XII 1957).

Chydorus gibbus Lilljeborg: Tamula järv (28. VI 1952), Tündre järv (30. VII 1952), Ruhijärv (24. VIII 1956), Dusiose järv Leedu NSV-s (19. VII 1957, leg. V. Kõvask).

Bythotrephes longimanus Leydig: Ähijärv (21. VII 1957).

\section{KIRJANDUS}

Birge, E., 1918. The Water Fleas (Cladocera). Ward, H. and Whippel, G., Freshwater Biology. New York.

Herr, O., 1917. Die Phyllopodenfauna der preussischen Oberlausitz und der benachbarten Gebiete. Abhandl. naturforsch. Gesellsch. Görlitz, Bd. 28.

L ill je borg, W., 1900. Cladocera Sueciae. Nova Acta R. Soc. Scient. Upsaliensis, Ser. III, vol. 19. Upsala.

M ä emets, A., 1958. Andmeid Eesti vesikirbuliste (Cladocera) faunast. ENSV TA Toimetised, Biol. seeria, VII köide, nr. 1.

Ocioszynska-Bankierowa, J., 1934. Zur Morphologie, Systematik und geographischen Verbreitung der Cladoceren-Gattung Scapholeberis Schoedler. Annales Musei Zoologici Polonici, T X, Nr. 16.

Poulsen, E. M., 1928. Faunistische und biologische Untersuchungen über die Cladocerenfauna von Dänemark. Vidensk. Medd. Dansk. naturh. Foren., Bind 86. København.

R a mult, M., 1930. Untersuchungen über die Cladocerenfauna des polnischen Ostseeküstenlandes. Bull. Intern. Acad, Polonaise, Serie B II, N. 5-6. Cracovie.

Ri ikoja, H., 1934. Eesti järvede nimestik. Tartu Ullikooli juures oleva Loodusuurijate Seltsi aruanded XLI (1-2). Tartu.

S a r s, G. O., 1890. Oversigt af Norges Crustaceer, II. Christiania Videnskabs-Selskabs Forhandlinger, N. 1. Christiania.

Stenroos, K. E., 1895. Die Cladoceren der Umgebung von Helsingfors. Acta Soc. pro Fauna et Flora Fennica XI, Nr. 2.

Stenroos, K. E., 1897. Zur Kenntnis der Crustaceenfauna von Russisch-Karelien. Acta Soc. pro Fauna et Flora Fennica XV, Nr. 2.

Б ен ин г А. Л., 1941. Кладоцера Кавказа. Высокогорная биол. станщия Наркомпроса Грузинской ССР. Тбилиси.

Ве ре щ а гин Г. Ю., 1912. К планктону оз. Великого, Новгородской губ. Работы из лаборатории зоол. кабинета Имп. Варшавского университета, Вып. 2, Варшава.

К ор д э Н. В., 1926. Группировки Cladocera, Rotatoria и Turbellaria. Кордэ Н. В., Ласточкин Д. А. и др. Прибрежные сообщества Валдайского озера. Ленинград.

Л ин ко А. К., 1900. О Cladocera Соловецкото острова и Белого моря. Работы зоолог, и зоотом. кабинетов Имп. СПБ Университета. Труды Имп. С. П. Общ. Естествоиспытателей, том. XXX, вып. 4, № 11.

Н ов и к ов А. В., 1910. К планктону Зауральских озер. Записки Уральского общ. любит. естествознания, том, XXX, 
Оп арина-Х аритонов а Н. Я., 1925. Материалык фауне Cladocera Чердынского края. Изв. Биол. научно-иссл. института и Биол. станции при Пермском гос. университете, том III, вып. 10.

С и д о р о в К. и В и н бе р г Г., 1928. Исследования по изменчивости Scapholeberis mucronata и Scapholeberis microcephala из водоемов в окрестностях Звенигородской гидрофизиологи'ческой станции. Применение методов физической химии к изучению биологии пресных вод. Труды Звенитородской гидрофизиологической станции Института экспериментальной биологии ГИНЗА. Москва.

Я ц е н ко А., 1928. Комбинированное влияние активной реакции, температуры и света на размножение Chydorus sphaericus. Труды Звенигородской гидрофизиологической станции Института экспериментальной биологии ГИНЗА. Москва.

\section{СИСТЕМАТИКО-ЭКОЛОГИЧЕСКИЕ ДАННЫЕ О НЕКОТОРЫХ ИНТЕРЕСНЫХ ВИДАХ ВЕТВИСТОУСЫХ РАЧКОВ (CLADOCERA) ЭСТОНИИ}

\section{А. х. Мяэметс}

\section{Резюме}

В статье приводится описание нового вида Alona estonica n. sp. (рис. 1; микрофото 1,2 ) и указываются различия между ним и другими, близкими ему видами (ср. рис. 2). Помимо этого, рассматриваются морфология, экология и распространение некоторых других ғедких видов ветвистоусых рачков (Cladocera) Эстонии.

\section{Alona estonica n. sp.}

Опи сание вида. ㅇ. Верхний край головы и створок равномерно умеренно выпуклый. Задне-верхний край и задне-нижний угол створок закругленные; задний край слабо выпуклый. Нижний край створок слабо выгнутый в середине или почти прямой. Нижний край створок покрыт относительно длинными волосами. Рострум широкий и притупленный, направленный вниз. Нижний край головы S-образно изогнутый. Ретикуляция створок выражена в виде слабо заметных продолыных линий; в других случаях створки покрыты мелкими бугорками (f. tuberculata n. forma - рис. 1, 4). Глаз лишь незначительно крупнее пигментного пятна или равен ему по величине. Пигментное пятно расположено немного ближе к глазу, чем к концу рострума.

Передние антенны коготкие. (не доститающие конца рострума); вдоль переднего края антенны несколыко нарезок, вооруженные каждая небольшим шипом. Чувствительная щетинка и одна папилла находятся в дистальной части заднего края (рис. 1, 1). Задние антенны с относительно длинными шипами на первом членике внешней и на дистальных члениках обеих ветвей. Губа дисталыно суживающаяся. Край губы слегка волнообразный; на дистальном крае два небольших пучка волос (рис. 1, 3). Постабдомен относительно короткий, дистально суженный. Дистальный угол верхнего края постабдомена закругленныи, дистально выступает, образуя между ним и коготками сравнительно глубокую выемку. Верхний край постабдомена образуетугол в проксимальной части ряда анальных зубчиков, а над анальным отверстием этот край вогнут. Проксимальный угол анального отверстия острый и сильновыступающий. Вдоль верхнего края постабдомена два ряда крупных, дисталыно несколько увеличивающихся аналыных зубчиков, число которых в одном ряде 9-12, обыкновенно же 10-11. Р яд анальных зубчиков продолжаетсяпроксимально (на месте анального оверстия), в виде ряда мелких щетинок, расположенных обычно 2-3 группами.

На проксимальной части нижнего края постабдомена обычен выступаюший угол. Коготки относительно длинные, слабо изогнутые, каждый с одним базальным шипом. Длина 우 $0,33-0,50 \mathrm{~mm}$ ( $ᄋ$ ㅇ с партеногеническими яйщами $0,39-$ 0.50 мм). $\hat{\delta} \hat{\delta}$ не найден.

Диффе ренци альный диагноз: Имеет своеобразную форму и вооружение постабдомена. 
Т и п: № 1 ㅇ (препарат в глицерине-желатине) сохраняется в Институте зоологии и ботаники АН Эст. ССР.

М есто обнаружения ти па: Озерко в верховом болоте Лоосалу (Раплаский район), 16 XI 1955 г. Вообще в Эстонии найдено 17 (와) экземпляров из 9 водоемов (рис. 3 - карта распространения) вида A. estonica. Вид обнаружен в промежуток времени со 2 V по 16 XI, при температуре воды менее $15,8^{\circ}$, $\mathrm{pH} 4-6$ и содержании Са ${ }^{2}, 4-4,6 \mathrm{mr} / л$.

\section{Scapholeberis microcephala (Lilljeborg MS) G. O. Sars}

Данный редкий вид (рис. 4, 1; микрофото 4) найден в 10 водоемах Эстонии. Это озерки на верховых болотах и полигумусовые озера. Таким образом, около $1 / 3$ известных до сих пор местонахождений этого вида относится $к$ Эстонии. Причины, объясняющие редкость находок этого вида, следующие: 1) малая изученность водоемов верховых болот; 2) смешивание вида с видом S. mucronata. В Эстонии найдена и фоғма $S$. microcephala f. subcornuta G. O.Sars (pиc. 4, 2, 3; микрофото 5), которая имеет небольшой, направленный вверх рог. Мукро данной формы длиннее, чем у typica, но обычно меньше, чем у $S$. mucronata. Ретикуляция часто выражена не так ясно, как у tyрica. Самым характерным признаком, отличающим $S$. mucronata от вида $S$. microcephala, является строение передних антенн (рис. 5).

Ннститут зоологии и ботаники

Академии наук Эстонской ССР

Поступила в редакцию

21 VI 1958

\section{SYSTEMATISCH-ÖKOLOGISCHE BEMERKUNGEN ÜBER EINIGE INTERESSANTE WASSERFLOHE (CLADOCERA) ESTLANDS}

\section{A. Mäemets}

\section{Zusammenfassung}

Im Artikel wird die Beschreibung einer neuen Art Alona estonica n. sp. (Fig. 1: Mikrophoto 1,2) gegeben und diese neue Art mit anderen nahestehenden Alona Arten verglichen (Fig. 2). Zugleich enthält der Artikel Angaben über Morphologie, Okologie und Verbreitung einiger seltenerer Arten der Wasserflöhe Estlands.

\section{Alona estonica n. sp.}

Beschreibung. Oberrand des Kopfes und der Schale regelmässig gewölbt. Hinterer Oberrand und hintere Unterecke der Schale abgerundet; Hinterrand schwach konvex; Unterrand fast gerade oder wenig konkav. Unterrand der Schale mit verhältnismässig langen Haaren bedeckt. Schnabel (rostrum) breit, stumpf und nach unten gerichtet. Kopfunterrand S-förmig gebogen. Schale schwach oder sehr schwach längsgestreift, oder bisweilen mit Reihen von Höckerchen punktiert (f. tuberculata n. forma - Fig. 1, 4). Auge etwas grösser als das Nebenauge, oder gleich gross. Nebenauge näher dem Auge als der Schnabelspitze lokalisiert. Vorderfühler kurz, die Schnabelspitze nicht erreichend. Am Vorderrand der Vorderfühler einige mit Stächelchen bewaffnete Einschnitte; Tastborste und Papille am Hinterrande (Fig. 1, 1).

Die Distalglieder der beiden Hinterfühleräste und das erste Aussenastglied mit verhältnismässig grossen Stacheln. Lippe schwachwellig gerandet und gegen das Ende hin verjüngt. Unterrand der Lippe mit 2 Haarbündeln (Fig. 1, 3).

Postabdomen relativ kurz, distal verjüngt (Fig. 1, 5). O b e r r and des Postabdomens bildet am Ende eine abgerundete und distal hervorragende Ecke. Zwischen dieser Ecke und den Endkrallen ist ein verhältnismässig tiefer Einschnitt. Im proximalen Teil der Reihe der Analzähne bildet der Oberránd des Postabdomens eine Ecke. Afterrand konkav, seine Proximaleckespitz und stark hervorragend. Zahl der Analzähne in beiden Reihen 9-12, meistens 10-11. Die Zähne vergrössern sich gegen das Ende des Postabdomens. Die Reihe der Analzähne geht an der Afteröffnung in eine Borstenreihe über, die bis zur Proximalecke der Afteröffnung reicht. Die Borsten treten gewöhnlich in 
2-3 G ruppen a u f. Im proximalen Teil am Unterrande des Postabdomens eine hervorragende Ecke.

Endkrallen lang, wenig gebogen, jede mit einem Basaldorn.

Länge der $\circ$ † : $0,33-0,50 \mathrm{~mm}$ (mit parthenogenetischen Eiern $0,39-0,50 \mathrm{~mm}$ ). o $\hat{o}$ bisher unbekannt.

Differentialdiagnose: Die allgemeine Form und Bewaffnung des Postabdomens ist charakteristisch.

Ty p: Nr. 1 ○ (Glycerin-Gelatine Präparat). Im Institut für Zoologie und Botanik der Akademie der Wissenschaften der Estnischen SSR.

Fundort des Typs: Blänke im Hochmoor Loosalu (Bezirk Rapla).

Die Art wurde in Estland in 9 Gewässern (Fig. 3) in 17 Ex. (우) vom 2. V bis zum 16. XI gesammelt; Wassertemperatur $<15,8^{\circ}, \mathrm{pH} 4-6$, Ca ${ }^{*}$-Gehalt $2,4-$ $4,6 \mathrm{mg} / \mathrm{l}$.

\section{Scapholeberis microcephala (Lilljeborg MS) G. O. Sars}

Diese seltene Art (Fig. 4, 1; Mikrophoto 4) wurde in 10 Hochmoorblänken und polyhumosen Seen Estlands gefunden. Somit ist 1/3 der bisher bekannten Fundorte dieser Art in Estland lokalisiert.

Die geringe Zahl der Fundorte dieser Art hängt wahrscheinlich von folgenden Ursachen ab: 1) Die Hochmoorgewässer sind bisher noch ungenügend erforscht; 2) S. microcephala wird oft mit S. mucronata (O. F. Müller) verwechselt.

In Estland ist auch S. microcephala f. subcornuta G. O. Sars (Fig. 4, 2, 3; Mikrophoto 5) gefunden worden, die auf dem Kopf ein nach oben gerichtetes Hörnchen besitzt. Der Schalenstachel (mucro) ist bei dieser Form etwas länger als bei typica, jedoch meist kürzer als bei $S$. mucronata. Die Retikulation ist öfters nicht so gut ausgebildet als bei $S$. microcephala typica. Die beiden Arten sind am besten dem Bau der Vorderfühler nach zu unterscheiden (Fig. 5).

Institut für Zoologie und Botanik

der Akademie der Wissenschaften der Estnischen SSR

Eingegangen

am 21. Juni 1958 